\title{
DINÂMICA FLUVIAL QUATERNÁRIA NO VALE DO RIO DO CERVO- ZONA RÚPTIL CARANDAÍ / MOGI GUAÇU / SUL DE MINAS GERAIS
}

\author{
Antônio Pereira Magalhães (*) Elaine de Souza Trindade (**)
}

\section{INTRODUÇÃO}

Visando contribuir para a compreensão da história geomorfológica do vale do rio do Cervo e mesmo da região sul de Minas Gerais como um todo, buscou-se levantar e interpretar as evidências de ciclos deposicionais e interdeposicionais quaternários, tentando-se reconstituir os principais eventos da dinâmica fluvial do vale do rio do Cervo. Os estudos adquirem importância particular, dado que o vale insere-se em trecho da "Zona Rúptil Carandaí-Mogi Guaçu” (Wernick et alii, 1981), datada do Ciclo Brasiliano e reativada inclusive no Quaternário, pretendendo-se, portanto, identificar as possíveis influências tectônicas e estruturais desta zona de cisalhamento na dinâmica fluvial.

$\mathrm{O}$ vale apresenta cerca de $64 \mathrm{Km}$ de extensão e direção geral WSW-ENE, situando-se próximo à borda meridional do Cráton do São Francisco (Fig. 1). Abrange os municípios de Ouro Fino, Congonhal, Borda da Mata, Senador José Bento, Espírito Santo do Dourado, Silvianópolis e Pouso Alegre, em uma área aproximada de $1123,23 \mathrm{Km}^{2}$. Contou-se principalmente com dados de níveis aluviais do rio do Cervo e afluentes, cuja interpretação das sequências sedimentares serviu à identificação dos paleoambientes deposicionais.

Os resultados foram obtidos basicamente através da análise de cartas geológicas (1:250.000) e topográficas (1:50.000), imagens de satélite TM LANDSAT 5-banda 4 (1:100.000), fotografias aéreas (CEMIG, 1989; 1:30.000) e através de trabalhos de campo. A análise da área e frequência dos topos da bacia baseou-se em cartas topográficas, resultando em gráficos com classes altimétricas de $20 \mathrm{~m}, 40 \mathrm{~m}$ e $60 \mathrm{~m}$. Foram realizadas análises granulométricas e de conteúdo de matéria orgânica (método Walkley Black) de amostras de sequências dos níveis de terraços. O trabalho vem dar continuidade e em parte reconsiderar as informações obtidas em estudos anteriores na área (Magalhães Jr e Trindade, 1996).

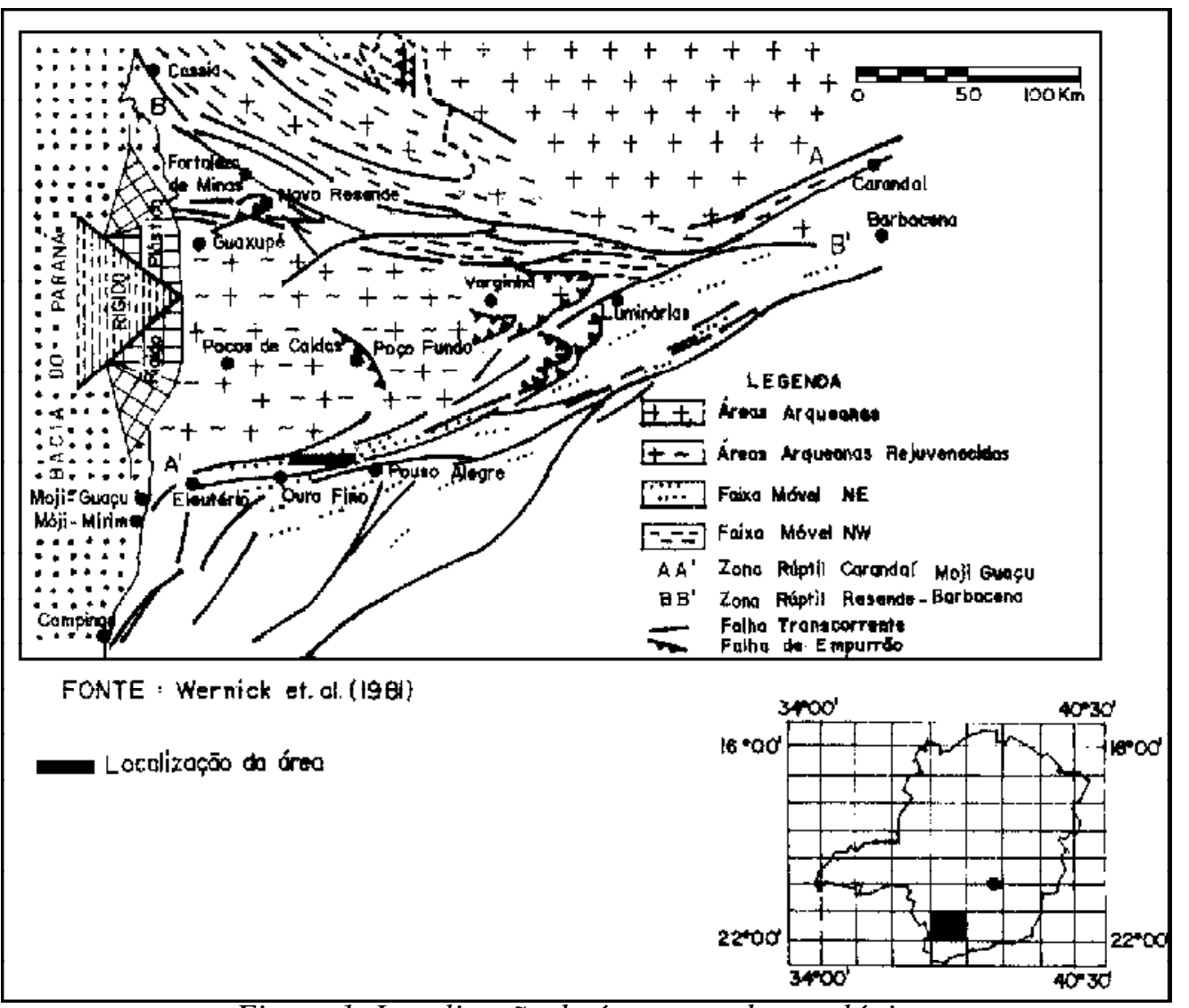

Figura 1: Localização da área e quadro geológico.

$\left.{ }^{*}\right)$ Prof. Dep. Geografia - IGC/UFMG

$\left.{ }^{(*}\right)$ Graduanda em Geografia - IGC/UFMG 


\section{SÍNTESE GEOLÓGICO-GEOMORFOLÓGICA}

O vale estudado apresenta-se escavado principalmente sobre os gnaisses do Complexo Itapira e granitos e migmatitos do Complexo Varginha. Em alguns trechos ocorrem ainda migmatitos do Complexo Amparo (trecho próximo à confluência com o rio Sapucaí) e os metamorfitos gnáissicos da Unidade Lambari, Complexo São João Del Rei (margem direita do baixo curso). Estas litologias, datadas do PréCambriano, pertencem à Associação Barbacena de Cavalcante et alii (1979)., encontrando-se recobertas por extensas coberturas aluviais neo-cenozóicas.

A região insere-se no Escudo Atlântico brasileiro, compartimento geoestrutural da Província Mantiqueira (Almeida et alii, 1981), cujos antigos embasamentos arqueanos apresentam-se cortados por grandes falhamentos associados a cinturões de cisalhamento. A “Zona Rúptil Carandaí-Mogi Guaçu” é constituída basicamente por falhamentos compressivos transcorrentes e inversos de direções predominantes NNE-SSW e ENEWSW, coincidindo com trecho da denominada "Descontinuidade Crustal do Alto Rio Grande" (Saadi, 1991).

A região sul do estado apresenta como principais domínios morfológicos a Serra da Mantiqueira, de direção geral NE-SW, e os Planaltos do Sul de Minas (IBGE, 1977), marcados por uma sucessão de degraus escalonados e basculados para NW a partir dos topos da referida serra. $\mathrm{O}$ vale do rio do Cervo insere-se no denominado Degrau Intermediário (Saadi, 1991), caracterizado por cristas alongadas na direção ENE-NE, como resultado da influência das zonas de cisalhamento regionais. Através de critérios geológicos e geomorfológicos, tornou-se possível a compartimentação longitudinal do vale em quatro segmentos, denominados A, B, C e D (Magalhães Jr e Trindade, 1997).

\section{DESCRIÇÃO E ARRANJO ESPACIAL DOS NÍVEIS E SEQUÊNCIAS DEPOSICIONAIS}

O aprofundamento dos estudos no vale do rio do Cervo resultou na reavaliação dos niveis deposicionais locais preliminarmente propostos (Magalhães Jr e Trindade, 1996). São encontrados quatro níveis deposicionais aluviais, sendo três níveis de terraços escalonados (T3, T2, T1-do mais antigo ao mais recente) e um nivel de várzea, parcialmente embutido no T1 (FIG. 2), cujas altitudes e alturas em relação ao nivel de base variam ao longo dos segmentos.

Foram elaborados perfís-síntese dos níveis de terraços tentando-se sistematizar o melhor possível a diversidade de sequências sedimentares encontradas (FIG. 3). Os níveis denominados T3 e T2 apresentam perfís semelhantes, constituídos por níveis basais de seixos de quartzo suportados recobertos por material argilo-arenoso (T3) a argiloso (T2) maciço marrom amarelado a marrom avermelhado. Percentuais de 60 ou até $71 \%$ de finos (argila + silte) foram encontrados nos depósitos do T2, dos quais 50 a 52 \% são de argila.
No T3, os percentuais de finos e argila são de 60 e 50 \% respectivamente. Baixos conteúdos de matéria orgânica foram encontrados em ambos os terraços: $0,57 \%$ no T3, e 0,89 a $1,59 \%$ no T2. Os terraços encontram-se mais representados na margem direita do vale, fato condicionado pela presença da Serra do Cervo na margemesquerda.

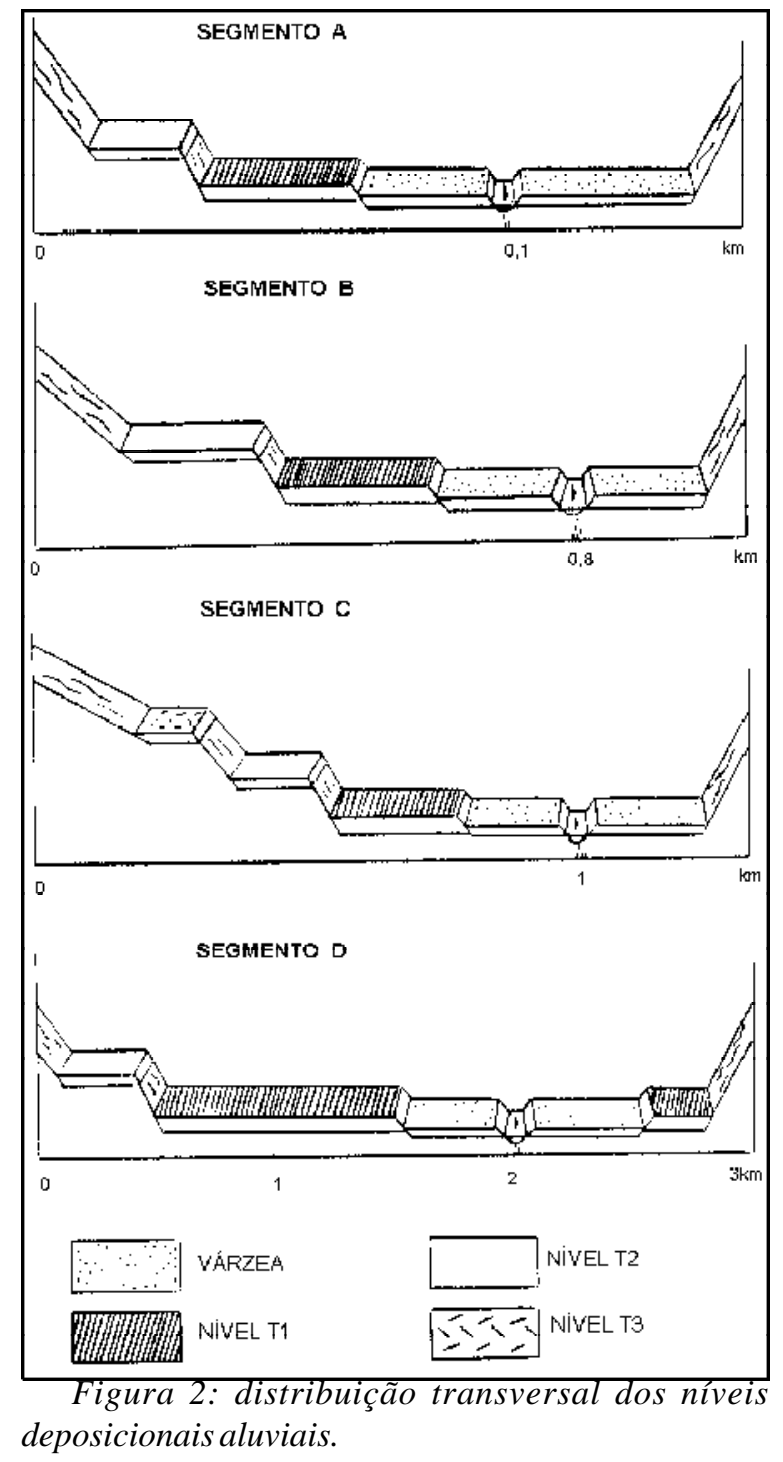

Onivel de terraço mais recente, $\mathrm{T} 1$, apresenta níveis basais de seixos de quartzo e do embasamento, recobertos por material argiloso na base tendendo a argilo-arenoso ou francoarenoso em direção ao topo, maciço marrom acizentado a preto, rico em matéria orgânica, e com mosqueamentos avermelhados. Nestes materiais de cobertura, foram encontrados percentuais de finos de 51 a $60 \%$ na base, dos quais 40 a $42 \%$ de argila, e $62 \%$ de finos e $39 \%$ de argila na porção superior. Os percentuais de matéria orgânica variam de 0,13 a até $6,58 \%$ no vale do Ribeirão Bicas.

O perfil-síntese do nivel de várzea constitui-se de dois ciclos deposicionais com nivel basal de seixos de quartzo recoberto por areia média a grossa esbranquiçada, e material argilo-arenoso a arenoargiloso marrom acizentado a preto, rico em matéria orgânica, em meio ao qual aparecem lentes de areia 
fina a média e mosqueamentos amarelados a avermelhados. São encontradas estruturas plano-paralelas e cruzadas acanaladas tanto nos níveis detríticos como no material mais fino.

Quanto aos depósitos de encosta, foi identificada uma sequência coluvial disseminada pelos quatro segmentos, mas com maior presença na margem direita do vale.
Constitui-se por stone-line basal de fragmentos de laterita e seixos angulosos de quartzo e das rochas do embasamento, recoberta por material areno-siltoso marrom avermelhado a amarelado. Em certos casos a sequência aparece recobrindo os depósitos do T3, mas nunca os níveis inferiores.

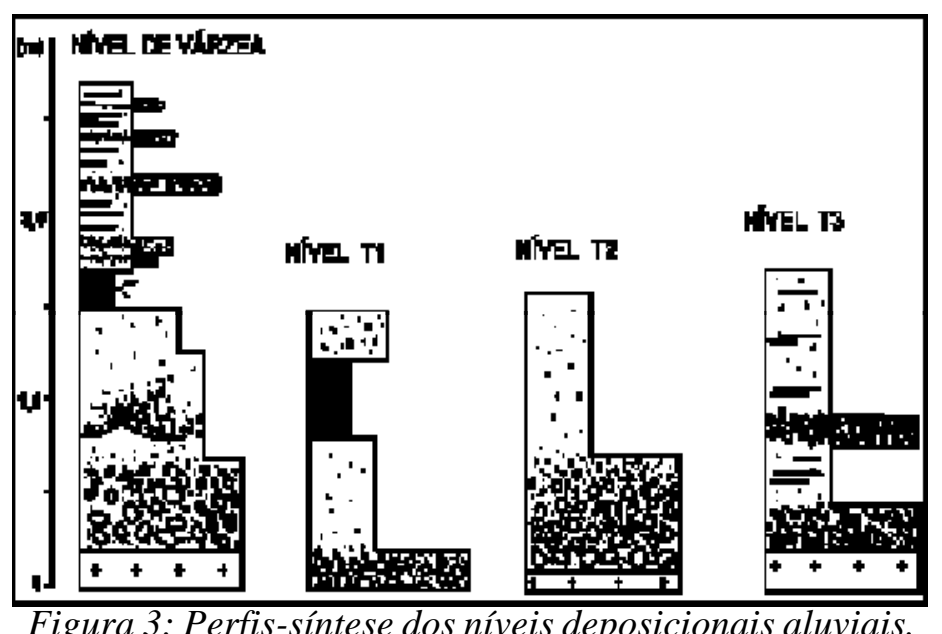

\section{PRINCIPAIS EVENTOS MORFODINÂMICOS CENOZÓICOS}

O evento morfodinâmico mais antigo efetivamente registrado na área corresponde ao T3, mas foi verificado que um ou mais níveis de terraços mais antigos certamente existiram. Suas evidências estão impressas principalmente em certos topos aplainados e patamares escalonados nas colinas da margem direita do vale. Encontram-se também seixos arredondados esparsos no colúvio da área, estando situados a altitudes superiores aos remanescentes do T3.

Pode-se considerar que estas fases deposicionais poderiam estar associadas a certos eventos correlativos da elaboração dos conhecidos ciclos de aplainamento regionais, segundo King (1956). Os remanescentes da Superfície Gondwana e Pós-Gondwana estariam preservados atualmente na região a altitudes de cerca de 1400-1500 m e $1000 \mathrm{~m}$ respectivamente. Ao referirse indiretamente à $S^{\text {a }}$ do Cervo, King relacionou os seus topos mais elevados à Superfície Pós-Gondwana, mas logicamente estes devem ser corretamente relacionados à Superfície Gondwana, já que situam-se entre 1200 e 1400 m. A Superfície Pós-Gondwana estaria portanto preservada em patamares e em topos rebaixados da serra.

Uma análise integrada dos gráficos referentes ao levantamento da área dos topos na bacia demonstra que uma das classes altimétricas de destaque, com um total de aproximadamente $3 \mathrm{~km} 2$, corresponde àquela entre 1.300 e $1.340 \mathrm{~m}$ de altitude (Gondwana?). Nesse nível altimétrico predominam as rochas graníticas do Complexo Varginha e ainda rochas cataclásticas diversas associadas às falhas do Espírito Santo do
Dourado e de Senador José Bento; neste caso os topos referem-se às cumeadas da serra do Cervo, na margem esquerda do rio. Encontram-se ainda em menor proporção, as rochas gnáissicas do Complexo Itapira, as quais sustentam a serra de Santo Antônio, a NW de Pouso Alegre.

Obviamente as superfícies de aplainamento não apresentam reconhecimento consensual, sendo difícil a comprovação de níveis tão antigos. Prováveis erros de medições altimétricas à parte, King também correlacionou os topos da região situados a cerca de $900 \mathrm{~m}$ de altitude, a remanescentes da Superfície SulAmericana, correspondendo aos topos das colinas da margem direita do vale. A análise da área dos topos na bacia demonstra que os topos com altitudes entre 850 e $1.000 \mathrm{~m}$ ocupam a maior área na bacia do rio do Cervo, com aproximadamente $25 \mathrm{~km} 2$, dos quais quase $56 \%(14 \mathrm{~km} 2)$ correspondem à área dos topos situados entre 880 e 920 m. Nesta área o modelado do relevo se desenvolve sobretudo sobre as rochas gnáissicas do Complexo Itapira e, em menor proporção, sobre os metamorfitos gnáissicos da Unidade Lambari.

Já no Quaternário, seria elaborado o T3 a cerca de $840 \mathrm{~m}$ de altitude, sendo encontrado apenas na margem direita do segmento $\mathrm{C}$, em posição de meia-encosta. A dissecação de uma paleocrosta laterítica seria responsável pelos fragmentos presentes em meio aos seixos. O mesmo nivel seria também desagregado por processos de encosta, resultando nos fragmentos encontrados no pacote coluvial da área, contemporâneo do T3 ou do ciclo de dissecação seguinte (o coluvio não recobre os níveis de terraços inferiores).

O elevado percentual de argila nos depósitos superiores do terraço (42\%) pode evidenciar a gênese 
do T3 sob condições tropicais úmidas, que podem ter sido condições semelhantes às atuais. Antes de análises mais detalhadas de identificação das argilas, não podemos ainda analisar a influência do clima úmido pós-sedimentar na formação das argilas presentes nos níveis deposicionais. Em uma região de reconhecida O vale do rio do Cervo apresentou uma dinâmica fluvial quaternária marcada por significativo controle tectônico.

O rebaixamento do nivel de base posicionou a calha do rio do Cervo a cotas de cerca de $830 \mathrm{~m}$ no segmento C. O T2 também é encontrado principalmente na margem direita deste segmento, e seu arranjo espacial bem como o mergulho das camadas para NW, evidenciam a recente fase de rápida migração do rio do Cervo rumo a margem esquerda do vale. Assim como no caso do T3, os seixos são exclusivamente de quartzo, atestando as condições tropicais úmidas favoráveis ao intenso intemperismo químico e homogeneização petrográfica. $\mathrm{O}$ elevado percentual de finos (até $71 \%$ ), e particularmente de argila (até 52\%), nos depósitos superiores, evidencia condições sin-deposicionais de clima úmido em ambiente de várzea.

Uma nova e curta fase holocênica de rebaixamento do nivel de base permitiu o posicionamento da calha fluvial no nível T1, situado a cotas aproximadas de $827 \mathrm{~m}$ no segmento $\mathrm{C}$. Este terraço confunde-se visualmente com o T2 e com a várzea, sendo identificado preferencialmente por critérios estratigráficos. Presença exclusiva de seixos de quartzo, predomínio de argila nos depósitos superiores e abundância de matéria orgânica evidenciam a continuidade das condições ambientais úmidas. A análise do paleoperfil longitudinal fluvial demonstra que o maior desnivelamento do T1 ocorre sobre a "Falha do Espírito Santo do Dourado" no segmento $B$, indicando sua provável influência na fase de rebaixamento do nivel de base entre os níveis T2-T1. O controle tectônico ativo da gênese dos baixos terraços resultou também na presença predominante do T1 na margem direita do vale.

A citada migração quaternária do canal rumo à margem esquerda pode ser explicada pela presença de um bloco estrutural tipo "hemi-graben", denominado Graben do Rio do Cervo (Magalhães Jr e Trindade, 1996). Sua formação e atividade estaria associada a soerguimentos na Serra do Cervo e movimentação de grandes falhas trancorrentes de direção ENE-WSW como a Falha de Jacutinga, que coincide com a base da serra. A reativação cenozóica de grandes falhas transcorrentes do sul do estado foi recentemente proposta por Saadi (1991), tendo o autor explicado que tal movimentação ocorreu através de deslocamentos individuais de blocos, soerguidos a SE e basculados para NW, resultando na orientação de escarpas como a da Serra do Cervo.

Os consequentes abatimentos da porção a sul da serra provocariam o basculamento do vale para NW e a rápida migração do canal, com a formação das extensas superfícies deposicionais na margem direita principalmente dos segmentos B, C e D. Com o "aprisionamento" da calha ao longo do graben, o considerável fluxo fluvial recebido de montante sob as vigentes condições tropicais úmidas seria quase todo dispersado na margem direita da maior parte do baixo curso, em função da presença da serra na margem oposta. Exceção é feita no contato dos segmentos B e C, onde a falha de Senador José Bento controla o canal próximo da margem direita, permitindo de forma anômala a maior extensão da várzea na margem esquerda.

A formação do T1 ao longo da calha principal seria também acompanhada pela sedimentação acelerada ao longo dos afluentes, onde são encontradas evidências do efeito remontante do "represamento". A propagação da formação de ambientes propícios ao entulhamento responderia por sequências deposicionais com predomínio de finos e abundância de matéria orgânica. Enquanto no T1 do rio do Cervo a matéria orgânica ocorre nos depósitos correlativos dos paleoambientes de planície, mas concentrando-se principalmente nas comuns sequências de meandros abandonados, nos vales de alguns afluentes esta acumulou-se intensamente em extensos ambientes de planície com tendência a brejos, com percentuais de até 6,59\%.

Foi posteriormente elaborado o nível de várzea através de pequeno encaixamento da drenagem. A dinâmica migratória do rio resultou na assimetria e escalonamento da várzea, marcada atualmente por no mínimo dois níveis topográficos distintos separados por cerca de $0,5 \mathrm{~m}$. Os depósitos finos orgânicos evidenciam típico ambiente de planície de inundação com abundância de meandros abandonados, inclusive no segmento A

Assim como os terraços, a várzea também é mais desenvolvida na margem direito do vale, como consequência do já citado processo de basculamento. O desvio do canal tem provocado o abandono gradual das porções superiores da várzea e a formação de diversas gerações de meandros abandonados na margem direita. As influências estruturais atuais são nitidamente visualizadas no contado dos segmentos B e C, já que esté é o único local onde o nível basal de seixos da várzea encontra-se acima do nível da água, fato devido ao brusco desnivelamento do perfil fluvial condicionado pela falha local.

A verificação de depósitos superiores (finos) T1 cortados por falha normal N60E, constituem claras evidências do atual controle tectônico da dinâmica fluvial do vale, sendo que tal direção coincide com a direçãio principal das falhas transcorrentes da Zona "Rúptil Carandaí-Mogi-Guaçu".

\section{FORMAÇÕES SUPERFICIAIS FLUVIAIS}

Deve-se mencionar a presença local de sequências detríticas de seixos angulosos a subangulosos de quartzo e principalmente do substrato, geradas "in-situ" através do intemperísmo das rochas do substrato. As 
análises granulométricas demonstraram pequenas variações entre os materiais superior e inferior ao nível detríticos, em todas as classes texturais. Em certos casos é visível a gênese dos seixos a partir da meteorização interna e fragmentação local dos afloramentos rochosos mais resistentes, preservados do intenso intemperismo e total remoção dos caracteres originais da rocha sã. Os seixos sub-arredondados derivam tão somente da eficaz atuação do intemperismo esferoidal.

A origigem "in-situ" também aplica-se a um nível de fragmentos laterísticos embasado e recoberto pelo substrato intemperizado. Eventos tectônicos recentes, mesmo que lentos, podem ter sido responsáveis pela total fragmentação da crosta laterítica e deformação do nivel detrítico citado acima, cujo arranjo espacial é marcado por fortes ondulações. O rebaixamento do lençol auxiliaria a migração do "front"de intemperismo para zonas mais profundas, homogeneizando o perfil.

\section{CONCLUSÕES}

O vale do rio do Cervo apresentou uma dinâmica fluvial quaternária marcada por significativo controle tectônico dos ciclos deposicionais, bem como dos ciclos de rebaixamento do nível de base, refletindo as reativações das estruturas da "Zona Rúptil CarandaíMogi Guaçu". Os registros sedimentares mais antigos foram totalmente removidos, fato que deve estar associado aos pulsos tectônicos cenozóicos responsáveis pela intensificação da dissecação erosiva. A acelerada morfodinâmica local refletiu-se na preservação de níveis aluviais apenas em situação de meia-encosta e fundos de vales.

Os terraços e a várzea demonstram uma gradual migração quaternária do canal rumo à base da Serra do Cervo, indicando os efeitos dos abatimentos relacionados ao Graben do Rio do Cervo. O "aprisionamento" da calha na margem esquerda e o basculamento do vale para NW seriam acompanhados da gênese de várias gerações de meandros abandonados, do mergulho das camadas fluviais do T2 para NW, do gradual abandono das porções superiores da várzea e do acelerado entulhamento na margem direita, propiciando ainda condições crescentes (do T3 à várzea) de marcante acúmulo de matéria orgânica na planície. Nos vales dos afluentes principais as planícies por vezes adquiriram nos ciclos mais recentes (T1 e várzea) caráter brejoso, refletindo os efeitos remontantes do entulhamento no nivel de base.

Apesar da análise estratigráfica dos niveis deposicionais demonstrar aparente ausência de condições sin-deposicionais sob ambientes climaticamente diferentes dos atuais (tropical úmido), posteriores análises de difração de raios X das argilas e datações de amostras locais poderão complementar os resultados, permitindo melhores correlações.

As influências tectônicas podem ser compreendidas através do efeito conjunto do reconhecido soerguimento epirogenético regional, cujos pulsos mais intensos seriam responsáveis pelos ciclos de maior rebaixamento do nível de base, e de movimentos diferenciais de blocos, principalmente o soerguimento da Serra do Cervo e os abatimentos do graben local. Os efeitos destes deslocamentos extendem-se ao período atual, tendo deslocado depósitos orgânicos holocênicos do T1 através de falha normal N60E. Este fato não nos causa surpresa quando sabe-se que o sul do estado é uma das zonas de maior frequência de abalos sísmicos do país, com destaque para municípios próximos ao vale estudado como Campanha, Pouso Alegre, Poços de Caldas e Guaranésia (Berrocal et alii, 1984).

Os deslocamentos devem ser analisados no contexto das reativações neocenozóicas da Zona Rúptil Carandaí-Mogi Guaçu (Wernick et al, 1981), também denominada Zona de Cisalhamento Ouro Fino (Hasui

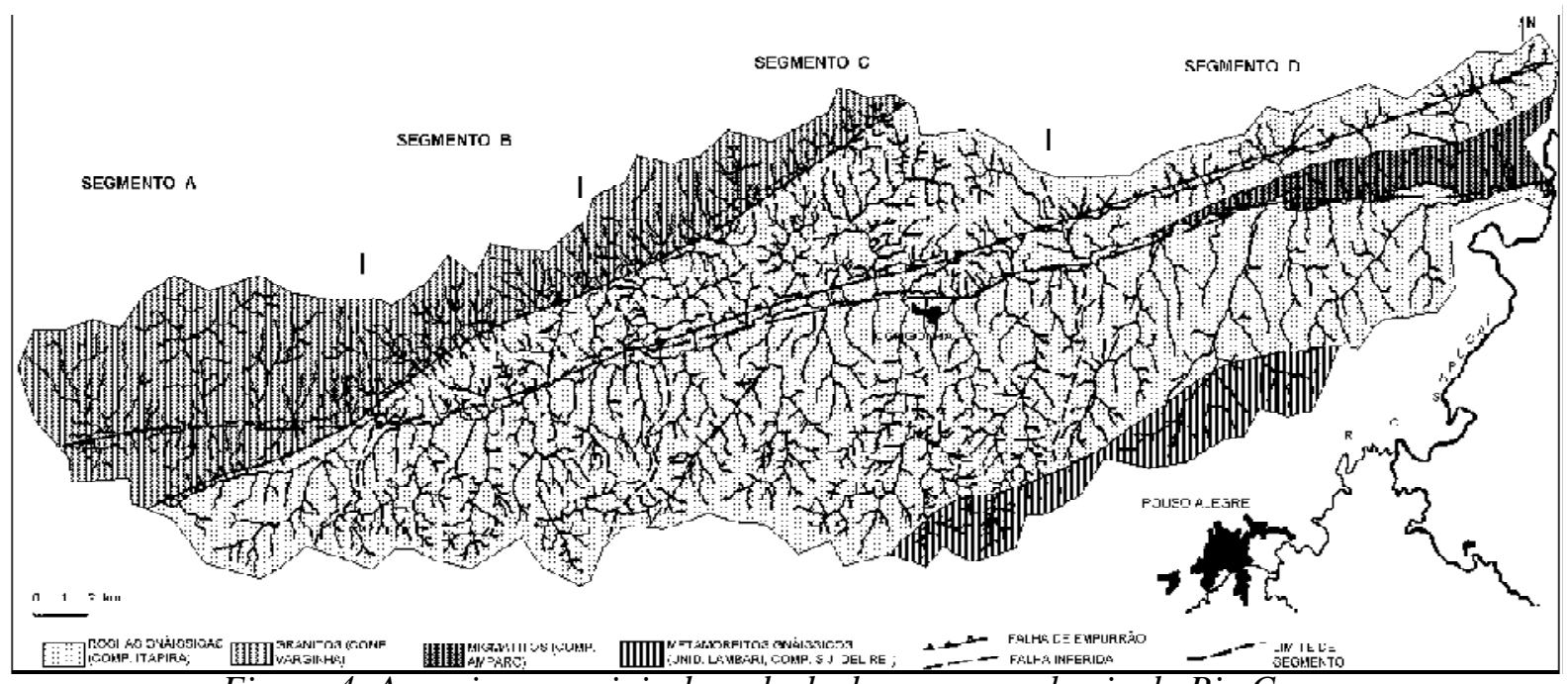

Figura 4: Arranjos espaciais da rede de drenagem na bacia do Rio Cervo. 
et al, 1980), e coincidente com trecho da Descontinuidade Crustal do Alto Rio Grande (Saadi, 1991), a qual engloba grandes falhas compressivas de caráter transcorrente com direção principal NE-SW, que foram geradas no pré-Cambriano (Ciclo Brasiliano) e reativadas até o Holoceno. Estas falhas são responsáveis pela fragmentação do relevo e pela direção de várias serras regionais, cujas cristas dissimétricas devem refletirem o basculamento de blocos locais.

Em termos da atividade neotectônica (Saadi, 1991), a área em estudo corresponde ao Segmento ItutingaSão Gonçalo do Sapucaí, compreendendo grande descontinuidade crustal. Os eixos de tensões obtidos para essa seção mostram compressão NNW-SSE e extensão SW-NE, com caráter transcorrente.

Os sistemas de falhas também respondem pelo forte desnivelamento no contato entre os segmentos B e C, com a Falha de Senador José Bento condicionando a ruptura do perfil fluvial longitudinal desde o ciclo T1. O controle estrutural também responde pela existência de padrões fluviais paralelos concentrados na margem esquerda do vale, com direção predominante NW-SE e ocorrência do padrão pinado coincidindo com as grandes falhas de Espírito Santo do Dourado e Senador José Bento, de direção NE-SW (FIG. 4).

$\mathrm{O}$ basculamento para NW foi também constatado em outros vales na região associados igualmente a serras de direção NE-SW. Os resultados vêm de acordo com as propostas de outros autores, tornando a existência do basculamento de morfoestruturas regionais um fato consensual. (De Martonne,1940; King,1956; Saadi 1991). O vale do rio do Cervo situaria-se justamente em um planalto inclinado para NW (Degrau Intermediário de Saadi, op.cit.), entre 2000 m na Serra da Mantiqueira a $900 \mathrm{~m}$ na base da Serra do Cervo.

Parece claro que os eventos neotectônicos na $S^{\mathrm{a}}$ da Mantiqueira têm condicionado a reativação de estruturas brasilianas nos Planaltos do Sul de Minas e controlado a dinâmica fluvial regional a partir da abertura do Atlântico Sul. Neste caso, os ciclos de acelerada deposição no vale estudado devem ser considerados no contexto regional, onde extensos sistemas de falhas transcorrentes e zonas de cisalhamento parecem ter condicionado os intensos ciclos de entulhamento recente no médio-baixo curso do rio Sapucaí, com efeitos remontantes ao longo de inúmeros vales como o do rio do Cervo, e formação de extensas várzeas e baixos terraços.

\section{AGRADECIMENTOS}

Agradecemos à PRPq e à FINEP pelo auxílio financeiro; ao CNPq pela Bolsa de Iniciação Científica e ao CPMTC-IGC-UFMG pelo apoio técnico.

\section{REFERÊNCIAS BIBLIOGRÁFICAS}

ALMEIDA, F. F. M de O Cráton do Paramirim e suas Relações com o do São Francisco. In: SIMPÓSIO SOBRE O CRATON DO SÃO FRANCISCO E SUAS FAIXAS MARGINAIS, Salvador, 1979. Anais... Salvador, SME-BA/SBG-BA, 1981, p. $1-10$.

ARTUR, C. A. e WERNICK, E. Modelos Geotectônicos Aplicados ao Pré-Cambriano Superior do NE do Estado de São Paulo e Áreas Adjacentes do Estado de Minas Gerais: Uma Discussão. In: Geociências. vol. 12. n. 1. São Paulo: Ed. UNESP, 1993, $155-185 \mathrm{pp}$.

BERROCAL, J. ASSUNPÇÃO, M.; ANTEZANA, R.; DIAS NETO, C. M.; ORTEGA, R.; FRANÇA, H.; VELOSO, J. A. V. Sismicidade do Brasil. São Paulo: IAG\USP\CNEN, 320 p., 1984.

BRAUN, O. P. G.; BAPTISTA, M. B. Considerações sobre a Geologia pré-cambriana da Região Sudeste e parte da Região Centro-Oeste do Brasil. In: REUNIÃO PREPARATÓRIA PARA O SIMPÓSIO SOBRE O CRÁTON DO SÃO FRANCISCO., 1977, Salvador. Anais... Salvador: SBG, Publ. Esp., 3, p. 225-350, 1978.

CAVAlCANTE, J. C. et alii. Projeto Sapucaí; Estado de Minas Gerais e São Paulo. Relatório Final... Brasília: Departamento Nacional de Produção Mineral, Série Geologia, Seção Geológica Básica, 2, 1979, 299 p.

HASUI, Y.; CARNEIRO, C. del r.; BISTRICHI, C. A. Estruturas e Tectônica do Pré-Cambriano de São Paulo e Paraná. An. Acad. Bras. Ciênc., v. 52, n. 1, p. 61-76, 1980.

HASUI, Y.; FONSECA, J. J. G.; RAMALHO, R. A Parte Central da Região de Dobramentos Sudeste e o Maciço Mediano de Guaxupé. In: SHOBBENHAUS, C.(coord.) Geologia do Brasil. 